\section{Risk management in clinical practice. Part 4. Endodontics}

\author{
J. Webber ${ }^{1}$
}

VERIFIABLE CPD PAPER
IN BRIEF

- Endodontics is an area of dentistry which gives rise to an increasing amount of complaints and litigation.

- Warning patients about the risks associated with endodontics is an important part of obtaining valid consent.

- Where treatment will be complex a referral to a specialist should be offered.

\begin{abstract}
Endodontic procedures are challenging and technically demanding. In the UK standards of treatment have been shown to have fallen short of acceptable guidelines, laying many dentists open to litigation on questions of clinical negligence by patients who understand and know what should be considered as current best practice in this area. Failure to communicate with patients about the procedure and not obtaining consent for treatment is a key area of complaint, as is inadequate record keeping. When treatment is undertaken within the framework of accepted guidelines it would be very difficult for a patient to open a claim for clinical negligence should a failure occur. This article looks at potential dentolegal problems in endodontics and how, through compliance with best practice, they may be avoided.
\end{abstract}

It is widely accepted that for many general dental practitioners the practice of endodontics is challenging and technically demanding. An unfortunate corollary to this is that on a worldwide basis the standard of endodontic treatment provided and its technical quality is poor and the

\section{RISK MANAGEMENT IN CLINICAL PRACTICE \\ 1. Introduction \\ 2. Getting to 'yes' - the matter of consent \\ 3. Crowns and bridges \\ 4. Endodontics \\ 5. Ethical considerations for dental enhancement procedures \\ 6a. Identifying and avoiding medico-legal risks in complete denture prosthetics \\ 6b. Identifying and avoiding medico-legal risks in removable dentures \\ 7. Dento-legal aspects of orthodontic practice \\ 8. Temporomandibular disorders \\ 9. Dental implants \\ 10. Periodontology \\ 11. Oral surgery}

Specialist Endodontist, Director, The Harley Street Centre for Endodontics, 121 Harley Street, London, W1G 6AX

Email: jw@julianwebber.com

www.roottreatmentuk.com

\section{Refereed Paper}

Accepted 20 October 2009

DOI: $10.1038 /$ sj.bdj.2010.721

${ }^{\circledR}$ British Dental Journal 2010; 209: 161-170 prevalence of endodontic infection therefore remains high, with many treatment failures, ${ }^{1-7}$ thus providing excellent ammunition for our implant colleagues.

In the UK, these problems have been highlighted by research on endodontics in the NHS, which is often regarded as falling short of what is considered as current best practice within the framework of guidelines published and laid down by the European Society of Endodontology (ESE).$^{8,9}$ Dummer showed that only $10 \%$ of cases treated by UK general dental practitioners could be considered as acceptable with reference to the ESE guidelines..$^{10,11}$

The ESE quality guidelines provide a statement of good practice for dentists about to embark on endodontic treatment and, perhaps more importantly for patients, a greater understanding of the procedure they are about to have. The guidelines include recommendations on:

- History, diagnosis and treatment planning

- Record keeping

- Infection control

- Maintenance of pulp vitality

- Root canal treatment

- Endodontic surgery

- Assessment of endodontic treatment

- Management of traumatic injuries.

McKoll et al. ${ }^{12}$ looked at the barriers to improving endodontic care among NHS practitioners and interviewed a cross sectional population of 12 dental practitioners to assess compliance of some of the parameters within the framework of the ESE guidelines in terms of treatment provided. Practitioners were interviewed on their compliance with the following: was rubber dam used for all endodontic procedures? Were radiographs taken to guide operative treatment, and to monitor tissue response to treatment? Were prepared canals filled with a semi-solid material (gutta percha) in combination with sealer rather than solid materials such as silver points or sealers containing strong organic compounds such as aldehydes? Was treatment monitored clinically and radiographically after treatment and success determined on the basis of tissue response and not just the abolition of reported symptoms?

Only a third of the group, which included more recent graduates, principals and associates, demonstrated a high level of compliance with ESE guidelines, while the rest of the group interviewed demonstrated an intermediate to low level of compliance. The reasons for non compliance were varied.

Jenkins, Hayes and Dummer ${ }^{13}$ looked at the nature of root canal treatment carried out by a group of dentists working in the UK. The majority of practitioners did not use rubber dam. Many did expose a 'length' radiograph and most practitioners used 
local anaesthetic as an irrigant rather than sodium hypochlorite. The majority used a potentially irritating antiseptic solution as an inter-appointment medicament rather than calcium hydroxide. Lateral condensation was used by half the surveyed dentists to fill anterior canals but only one third used it in posterior teeth. Only half checked the fit of the master cone before obturation. Two thirds used a zinc oxide based sealer and three quarters took a final post obturation radiograph. The authors concluded that a large percentage were using techniques with no evidence of clinical effectiveness.

What does all this suggest from a dentolegal standpoint? Many dentists in the UK, and elsewhere, where outcomes are poor are laying themselves open to litigation from patients who increasingly will know what treatment they should have received rather than what they actually did, with an inevitable rise of clinical negligence claims in this field.

\section{PRINCIPLES OF CONSENT AND ENDODONTICS}

The UK General Dental Council (GDC) has laid down guidelines on the question of standards of treatment by dentists and principles of patient consent. ${ }^{14,15}$ These issues are as appropriate to the practice of endodontics as any other branch of dentistry and have been dealt with elsewhere in this series. However, one of the major causes of litigation in endodontics occurs as a result of failure to make the patient aware of all the facts before commencing treatment and with this, a failure to receive consent from the patient that they are happy for the treatment to go ahead.

Field et al. and Lazarski et al. showed that although high, 100\% successful outcomes do not exist in endodontics, even in the best hands. ${ }^{16,17}$ Patients need to be made aware of and understand the complexities of treatment as well as the possibility of failure and the reasons behind this. It is too late to discuss failure with a patient after it has occurred.

Patients should be given the option of referral to an endodontist for difficult cases, especially where the practitioner is not skilled enough (Figs 1a-f). The American Association of Endodontists has produced guidelines to help general dentists understand case difficulty. ${ }^{18}$ The suggestion that
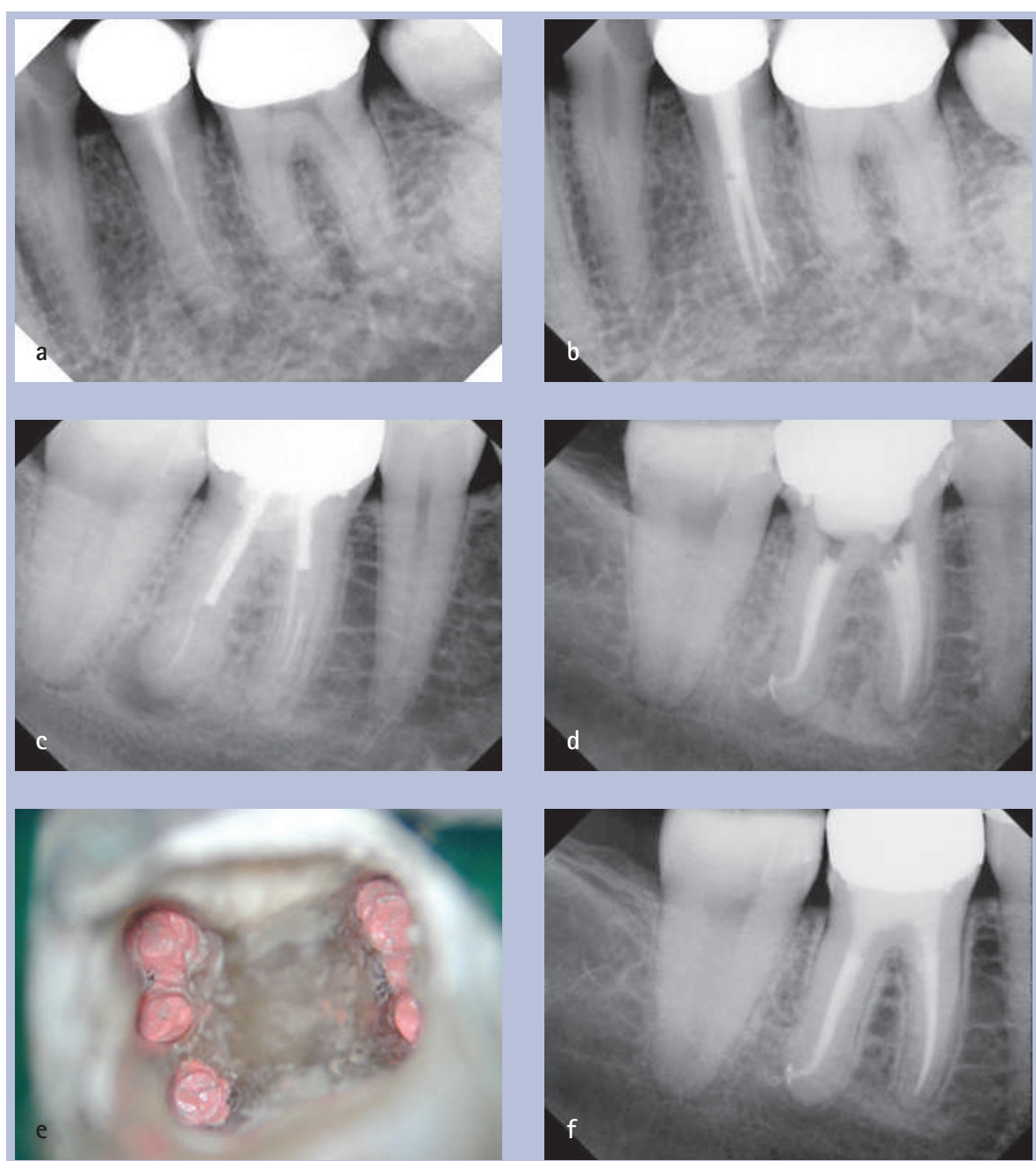

Fig. 1 a) Anatomically complex 35 requires retreatment; a suitable case for referral? b) Completed case 35 demonstrates three canals. Apical bifurcation extremely difficult to prepare and fill. c) 46 complex retreatment with crown, two posts, inadequate root canal treatment, apical area distally and separated instrument in MB canal; a suitable case for referral. d) 46 retreated successfully. e) 46 complex anatomy also apparent. Three mesial and three distal canals are present. f) 46 one-year recall, tooth restored and healing seen

the endodontic treatment cannot be carried out under the health service contract is unacceptable and there are NHS as well as private specialists who accept referrals. The suggestion that a high standard cannot be achieved by a dentist because of financial constraints is also unacceptable. Every dentist has a duty of care to do the best he or she can within the guidelines of best practice. If the dentist can demonstrate that treatment was undertaken within the framework of accepted guidelines, any failure, should it occur, can be defended.

We all know that endodontics can be uncomfortable after completion and it is therefore prudent to anticipate this by advising what can be done to alleviate the symptoms. Again, this is best explained before treatment, as is the fact that endodontic treatment can result in a weaker tooth that will most probably require cuspal coverage following the endodontic treatment. Since endodontically treated teeth can discolour this should also be discussed, as should the possible solutions.

The patient notes should reflect all of these scenarios and that these discussions have taken place. Where necessary and in the case of private treatment, patients should ideally be given a written quote for treatment and within the body of the correspondence, a list of the issues involved that could possibly lead to failure. In stating that endodontic treatment can never be $100 \%$ successful it is wise not to give a percentage estimate of probable success, stating instead that there is a very good chance that treatment will lead to 


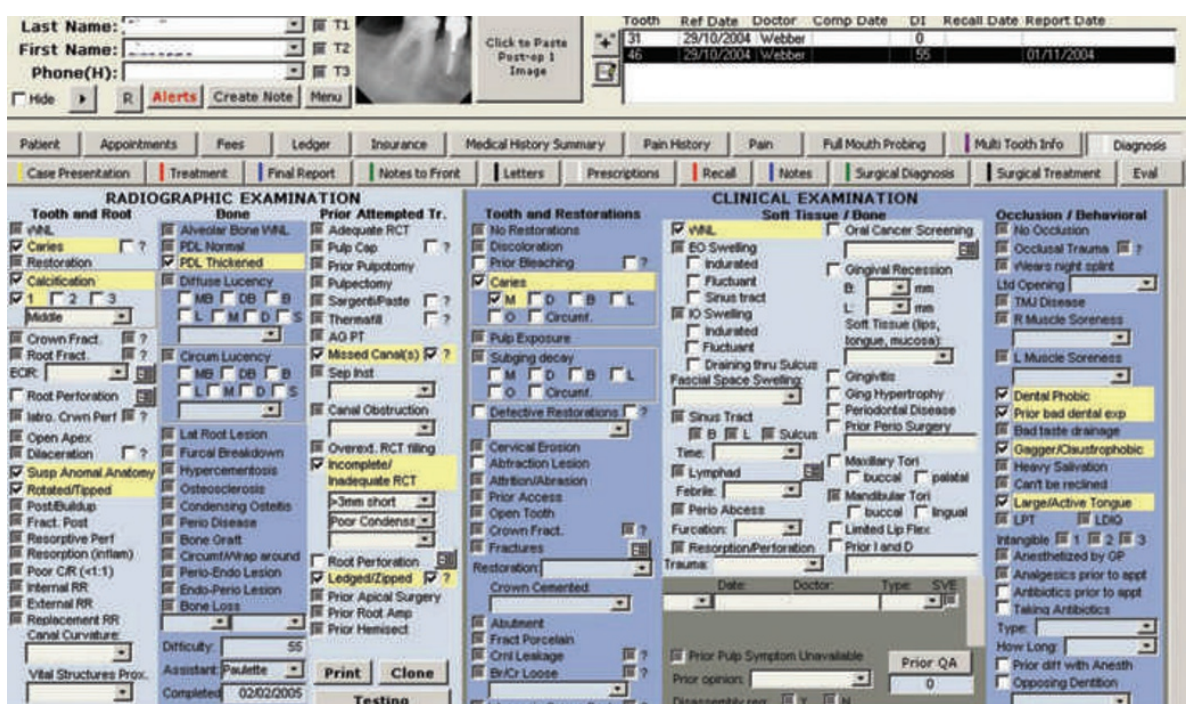

Fig. 2 The Digital Office: single tooth endodontic diagnosis page. (Courtesy of Dr Gary Carr, Dogbreath Software, San Diego, California, USA)

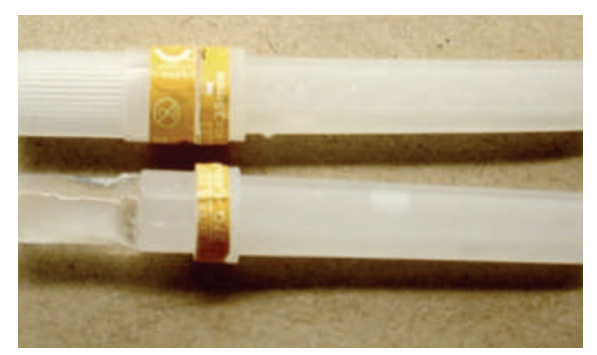

Fig. 3a Individual sticks of ice made from used needle cases

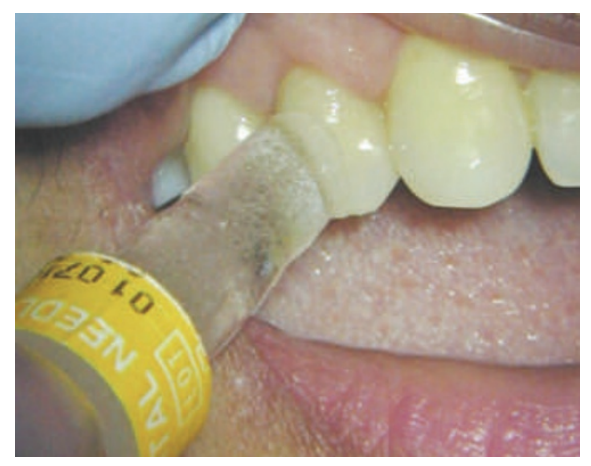

Fig. $3 b$ Sticks of ice testing individual teeth for sensitivity to cold

treatment when the diagnostic tests evoke a reproducible response which is the same as that which the patient complained of. If the response is not reproducible do not guess. Sometimes acute pulpal symptoms take time to localise and it is reasonable to invite the patient to return the next day so that the tests can be redone in order to ensure the right tooth is treated.

Many instances of acute pulpal and periapical symptoms occur after a recent restoration, small or large, and it is important to take the time to carry out an extensive endodontic examination, including radiographs, before a restoration. If it is possible to demonstrate that the state of the pulp is compromised before the preparation and restoration of a tooth then endodontics should be considered in advance. Abou Rass has called this situation the 'stressed pulp.21 It is always far better to undertake the endodontics first rather than have a problem after the restoration has been placed.

Many complaints arise when restorations are placed - either fillings or fixed restorations - and pulpal pain results shortly thereafter. If an assessment of the pulp suggests this may be a possibility it is important to warn the patient of this before placing the restoration, or at least immediately it is placed. Record this warning in the notes. 

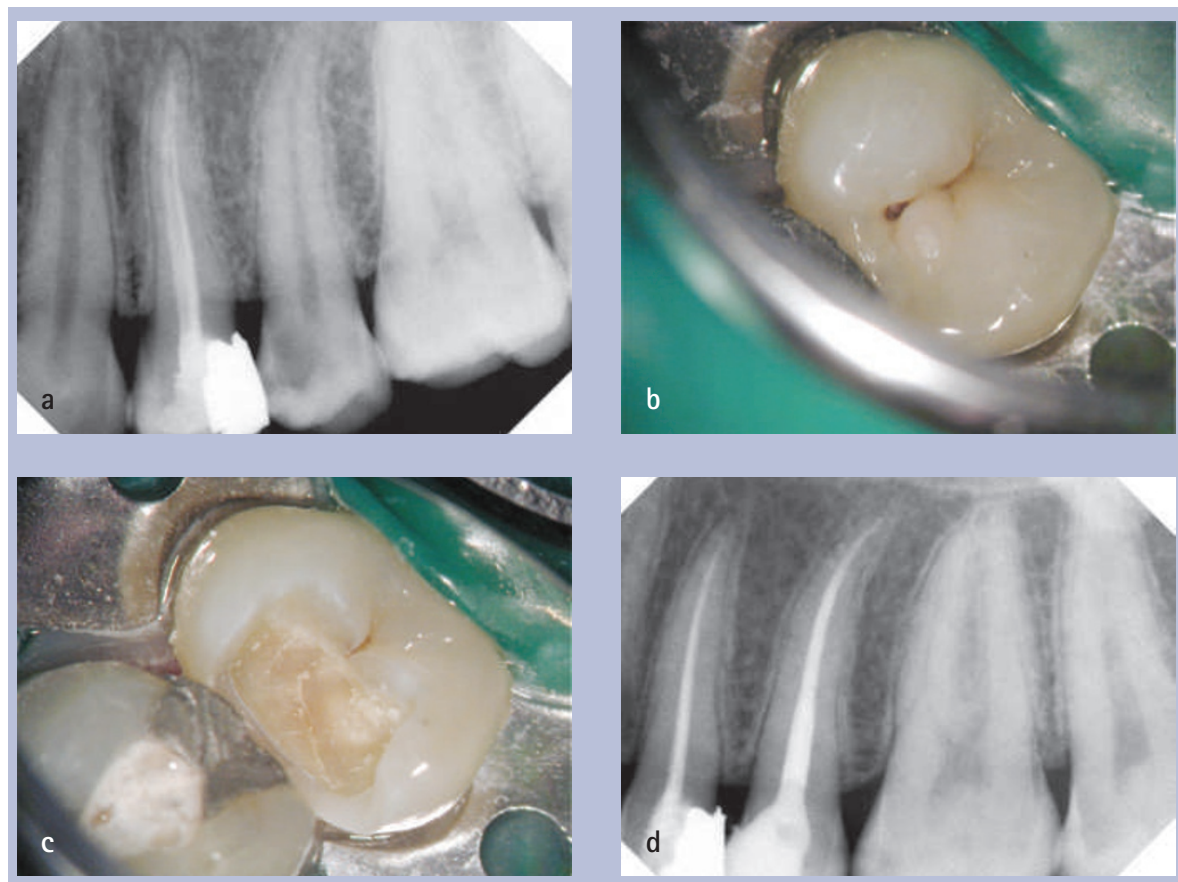

Fig. 4 a) Patient complained of severe sensitivity to cold with lingering pain in the $24,5,6$ region. No radiographs or clinical tests were undertaken. 24 was root treated. Pain remained after treatment. $\mathbf{2 5}$ had gross caries. b) Clinically $\mathbf{2 5}$ had no obvious external evidence of a problem but was exquisitely tender to cold. c) 25 with gross caries. d) Root canal treatment 25 complete. Symptoms eliminated but patient had two root treatments instead of one!

Teeth with extreme readings when using an electric pulp tester to assess pulp vitality (Fig. 5) should be investigated further before complex restorative work since if a tooth is nearly dead before the preparation, it surely will be after the restoration is placed. Many apparently vital teeth will become non-vital over a period of time when extensively restored..$^{22}$ Invariably, this problem happens after the restoration is placed and not during the temporary stage. This situation can be pre-empted before the crown, onlay, bridge or veneer is placed since there is nothing worse for a patient than to have their expensive crown ruined by an endodontic access cavity, especially if recently placed.

\section{Radiographic technique}

Poor radiographic technique can be avoided with appropriate care. Guesswork using the bisecting angle technique that distorts the length and curvature of the roots and does not demonstrate endodontic pathology adequately is an invitation to poor diagnosis. Many aiming and locating devices are available today to ensure a reproducible technique and while digital radiographs are quick to view (instant), any manual developing technique must ensure the film is accurately processed, washed and dried.

To defend oneself with a poor radiograph is like going into battle without any armour. Quite simply if the radiograph is poorly developed, does not provide the correct information or is impossible to interpret, mounting a defence based on it would be ill-advised (Figs 6a and b).

Good radiographic technique must also be applied to the question of length control in endodontic treatment. A radiograph with an instrument in the canal and/or a gutta percha cone at the correct length indicates that every effort has been made to ensure that root filling material is not inadvertently extruded through the apex of a tooth to a degree whereby the outcome could be undermined (see below). The length of the canal must be recorded in the patient record.

Whether electronic apex locators (EAL) can be used as the sole means of length determination without a radiograph is an interesting question, as they are widely used in endodontics and are very accurate. Shabahang et al. ${ }^{23}$ tested the accuracy of the Root ZX apex locator (J. Morita) and showed it to be accurate in up to $96 \%$ of cases in locating the apical foramen. The

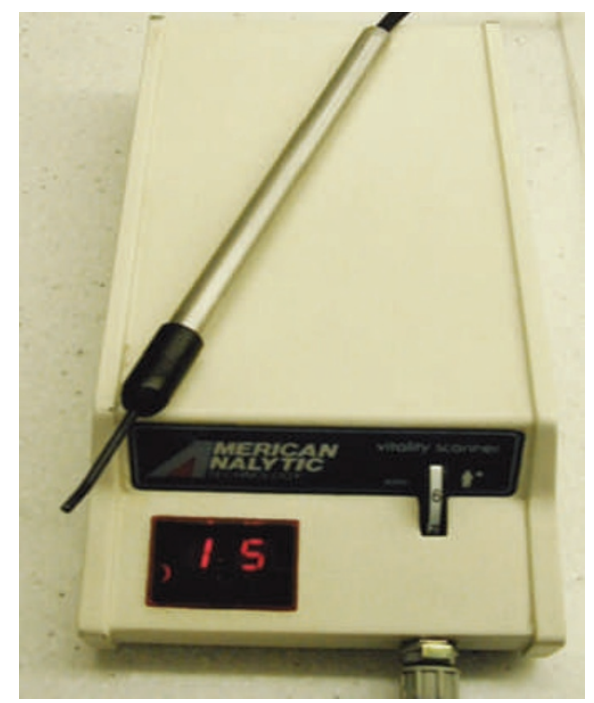

Fig. 5 Analytic Technology Pulp Tester (Sybron Endo), necessary diagnostic armamentaria

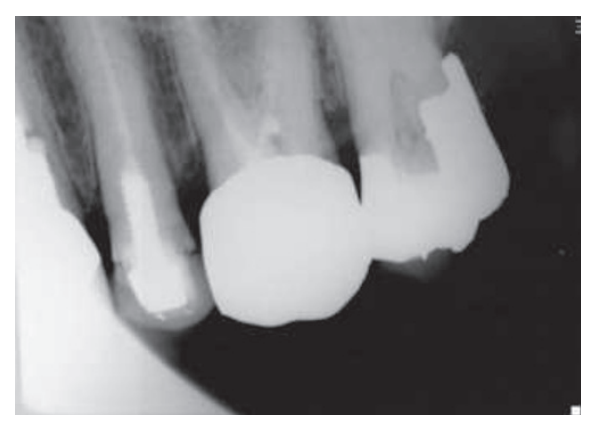

Fig. 6a Poor radiographic technique demonstrates little, least of all periapical status of upper left quadrant

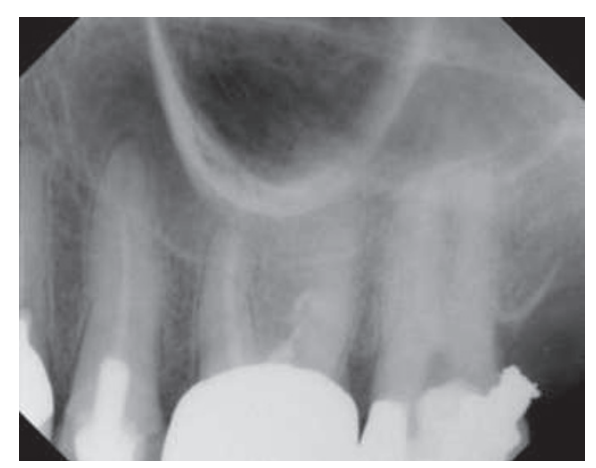

Fig. 6b Good long cone periapical radiograph of upper left demonstrating restorative, periodontal, endodontic and apical status of all teeth in region

answer is therefore yes, but the reality is that where the result is a root filling that is very short or indeed very long and there is no evidence of any radiographic length control, the excuse that an EAL was used (even though the literature suggests that these devices are accurate) and the radiographic reality suggests a poor result would be indefensible. It is therefore imperative to always take a control radiograph 

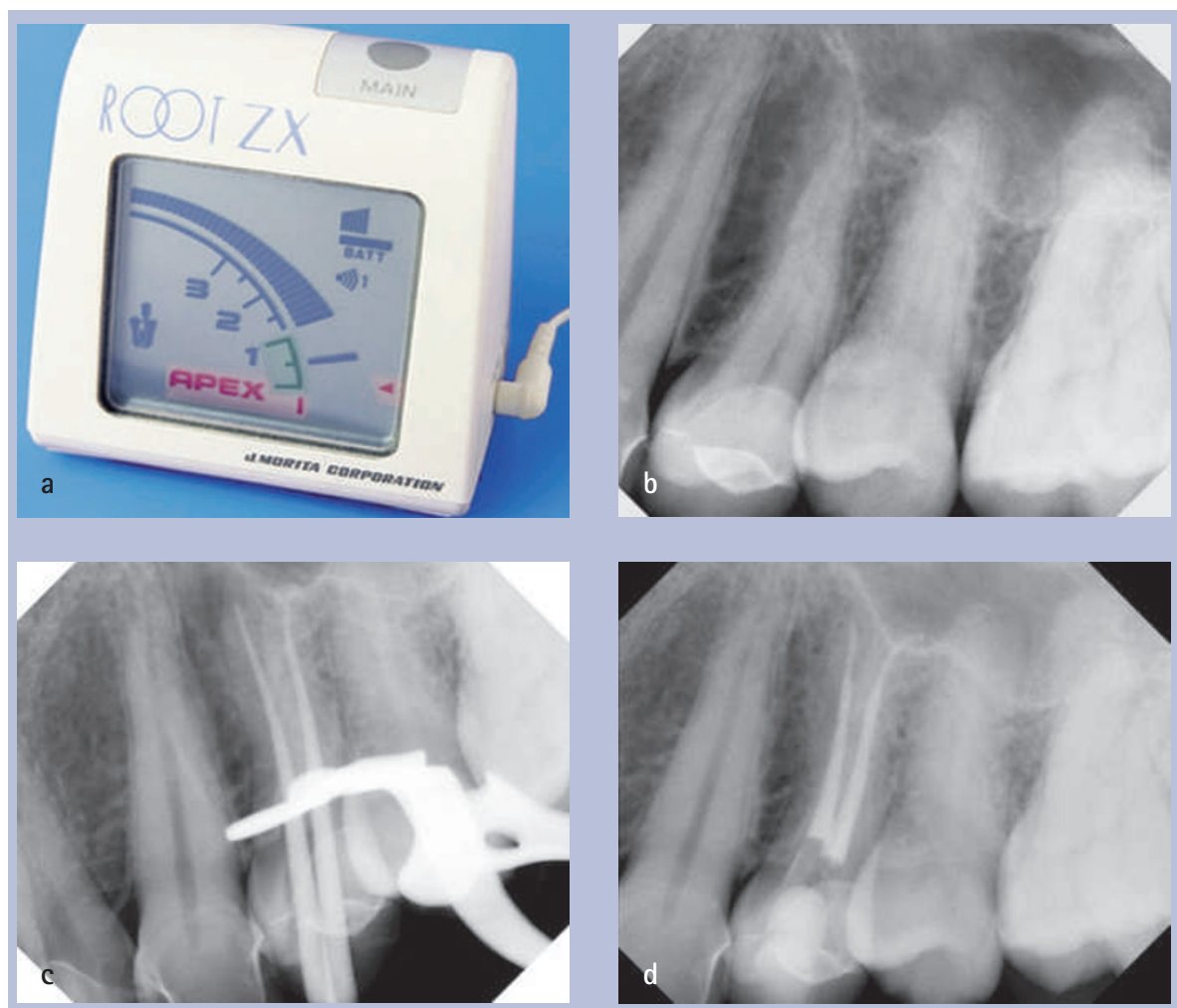

Fig. 7 a) Root ZX electronic apex locator (J Morita, Japan). b) 24 requires root canal treatment. c) Canals prepared without working length radiograph but EAL was used. The length was confirmed with a master cone radiograph. d) 24 root canal treatment complete

with an instrument and/or a gutta percha cone (Figs $7 \mathrm{a}-\mathrm{d})$.

\section{Rubber dam}

Nowhere is the use of rubber dam more relevant than in the practice of endodontics. However, it is seldom used for endodontics despite the knowledge that it ensures an aseptic environment and entirely prevents ingestion of instruments. ${ }^{24,25}$ There are no situations where rubber dam cannot be applied and general practitioners should take the time to learn how to place rubber dam correctly and avail themselves of one of the many courses on placement.

Rubber dam serves to protect the airway as well as preventing caustic solutions such as hypochlorite being inadvertently ingested. In the absence of rubber dam it is impossible to defend a claim where a patient has swallowed or inhaled a hand file. Rotary files are increasingly being used, but hand files are still required in most protocols for initial instrumentation and can be swallowed or inhaled during canal instrumentation or exposure of radiographs unless rubber dam is used.

\section{Fractured teeth}

The majority of teeth requiring root treatment invariably have large restorations to start with. It must be assumed that an endodontic access cavity would further weaken such a tooth and there is certainly much literature to support this statement. Therefore, in order to prevent a root filled tooth from fracturing, it should be adequately restored after the procedure with a post where necessary and the minimal requirement of cuspal coverage (Figs $8 \mathrm{a}$ and b). ${ }^{26-28}$

With this knowledge, before endodontic treatment all patients should be made aware of the possibility of tooth fracture after the procedure and the need to have the correct restoration. All of this information must be recorded in the patient record along with information to show that the patient clearly understood the potential problems should the tooth not be restored properly. In addition, the need for a good restoration to provide adequate coronal seal as part of an endodontic-restorative continuum must be stressed. There is a considerable body of literature on this issue but the reality is that root filled teeth leak from coronal to apical as much as they do from apical to coronal. ${ }^{29}$ Without

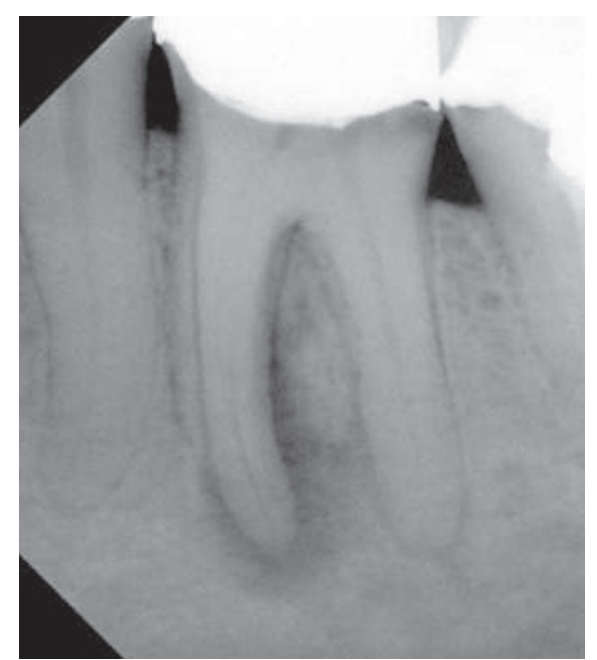

Fig. 8a 36 with poorly fitting crown, caries and apical area

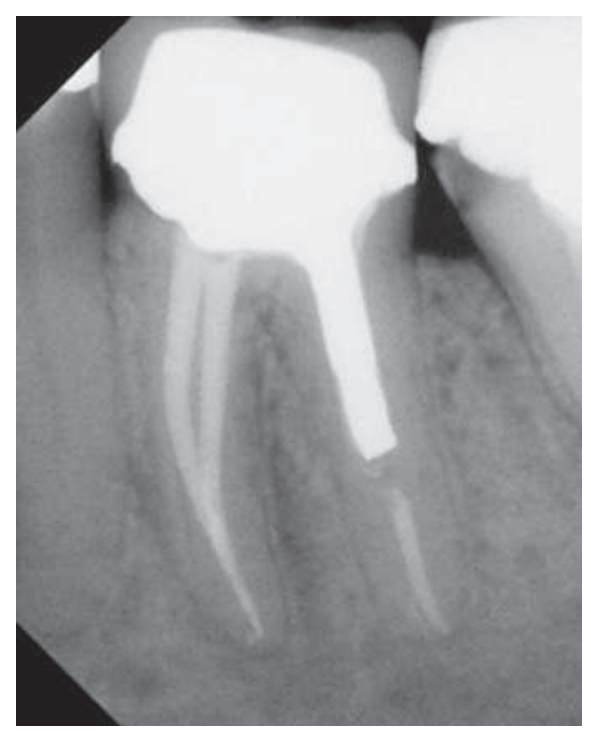

Fig. 8b 36 successfully root treated. Restored with post core and crown. Excellent healing at one year

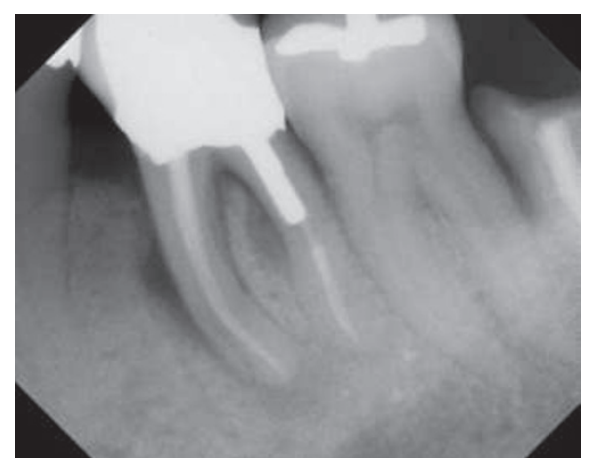

Fig. 9 Catastrophic fracture $\mathbf{3 6}$ despite excellent root canal treatment and restoration

the correct restoration, acquired endodontic infection can be expected to occur and failure is eventually likely.

A tooth which is well root filled and adequately restored can of course sadly fracture at a late stage (Fig. 9). If the 
patient has been advised of the restorative requirements of a root filled tooth and then received a correctly and adequately placed restoration (bonded core and/or cuspal coverage) and this unfortunate scenario occurs, the question of negligence and litigation cannot occur. Conversely, a poorly advised patient with little or barely adequate post-endodontic work would have a suitable case for negligence should a root filled tooth subsequently fracture. The timing of the placing of extra-coronal restorations after endodontics is the subject of some debate.

A clinical study by Nagasiri and Chitmongkolsuk $^{30}$ showed that survival rates of endodontically treated molars without crowns at 1, 2, and 5 years were 96\%, 88\% and 36\%, respectively. With greater amounts of coronal tooth structure remaining, the survival probability increased.

\section{Broken (separated) instruments}

Any metal instrument when used in a root canal is subject to breakage. All metals can be stressed beyond their modulus of elasticity and at this stage are prone to separation The advent of nickel titanium in rotary root canal preparation has further compounded this problem despite the excellent flexibility of these files (Figs 10a-e).

Root canal instruments fail for two reasons: either flexural fatigue, which occurs mainly due to instrument overuse, or torsional fatigue, which occurs due to the forces on the instrument in rotation preventing movement, locking and fracture. ${ }^{31-33}$ Pruett et al..$^{34}$ looked at the issue of 'cyclic fatigue' and concluded that all rotary nickel titanium (RNT) instruments have a finite number of rotations to failure. Simply put, the more you use an instrument the more likely it is to fracture. Torsional failure occurs when a rotating instrument is placed into a canal that has not been scouted and preflared by hand ISO files first. Attempting to force an instrument into this tight situation will result in taper lock and subsequent fracture.

Rotating rotary instruments should also be used with a suitable endodontic motor, preferably with torque control to eliminate these dangerous forces but also to restrict the number of rotations. ${ }^{35,36}$ The majority of RNT instruments should run at 250-350 rpm and a reducing handpiece
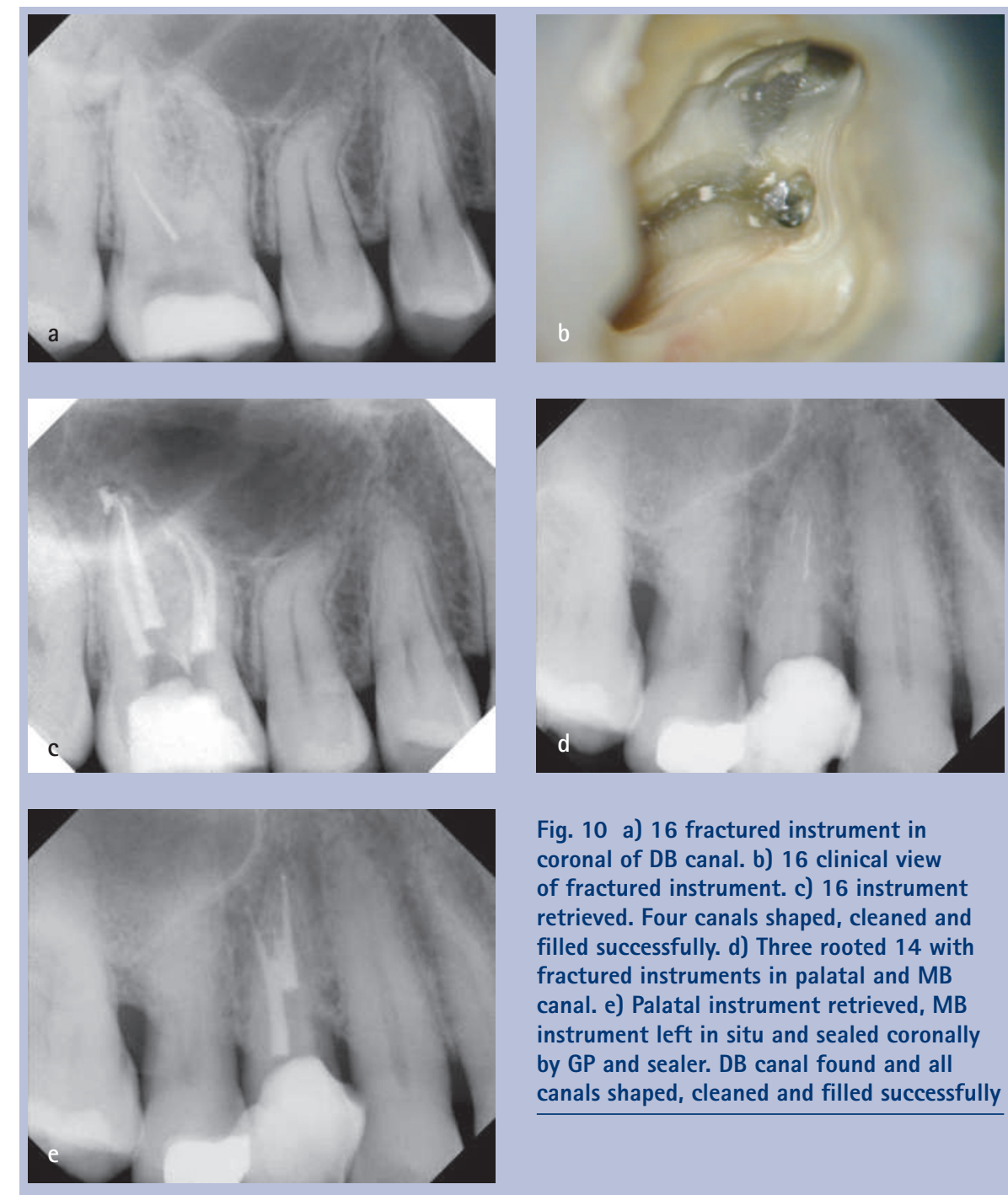

Fig. 10 a) 16 fractured instrument in coronal of DB canal. b) 16 clinical view of fractured instrument. c) 16 instrument retrieved. Four canals shaped, cleaned and filled successfully. d) Three rooted 14 with fractured instruments in palatal and $M B$ canal. e) Palatal instrument retrieved, MB instrument left in situ and sealed coronally by GP and sealer. DB canal found and all canals shaped, cleaned and filled successfully

is required to provide $16: 1$ or $20: 1$. Attempting to run a rotary instrument on a 1:1 handpiece is an invitation to disaster. Should fracture occur it would be indefensible should a patient wish to pursue the matter as negligence. If general practitioners are to use these instruments successfully, then the manufacturers' guidelines should be adopted and there can be no exception to this.

This leads us to one of the most frequent causes of litigation in endodontics: failure to notify a patient that an instrument has fractured. When all the guidelines have been followed and overuse is not an issue, instruments can still fracture. Operator experience is a consideration here but the fact of the matter is that if an instrument breaks (call it separation if you wish), the patient must be informed. In addition, an explanation of the potential problems as a result of this incident must be given as well as what you are able to do to rectify the situation. It is indefensible not to inform a patient if instruments are separated in root canals or beyond them. Ensure all facts are recorded in the patient record and that the patient has understood the implications of any discussion. The patient should be advised of the options which may include monitoring and referral to specialist.

An instrument that breaks early in the procedure assumes the canal is not clean. Failure is likely, unless the instrument can be removed. An instrument that fractures at the end of the procedure assumes the canal has been cleaned, especially if the instrument is apically positioned. Saunders et $a l .{ }^{37}$ have shown that a sufficiently large instrument separated apically and then sealed with gutta percha and an approved sealer will prevent bacterial leakage. Furthermore, location also dictates whether it could or should be removed.

Not all broken instruments can be removed and some can be left. A strategy 
is needed to make a decision as to what is the best way forward. ${ }^{38}$ Who should make the decision? Under the circumstances a referral to a specialist would be advisable and the final decision should be theirs. If the referral is private you may wish to offer to pay for any consultation and subsequent treatment, but the practitioner should always check with their defence society before taking such a step. It is not an admission of negligence if you offer to pay, more of an effort to demonstrate your care and concern that the patient will be comfortable and that their tooth is saved.

It is not negligent to separate an instrument in a canal but failing to inform the patient and manage it appropriately may well be.

\section{Single use of endodontic files and reamers}

The Chief Dental Officer's advice on the single use of endodontic files and reamers that have been in contact with pulpal tissue $^{39}$ underlines concerns of the possible transmission of variant Creutzfeldt-Jakob disease from patient to patient via this route despite the very best cleaning and disinfection procedures. This is a concern for the future health of the UK public despite the lack of any real evidence. ${ }^{40}$

However, all GDPs and specialists, NHS or private, are expected to follow these guidelines with no exception. The guidelines are open to interpretation and dentists must review their own decontamination and sterilising procedures in relation to items other than files and reamers (specifically mentioned), such as Gates Glidden drills, burs and clamps, and re-use these products only where they are satisfied the risk element is minimal. It is a matter of conjecture should there be a challenge on this issue as to where a dentist would stand since the recommendation states endodontic files and reamers only.

It has been suggested that endodontic files and reamers can be re-used on the same patient. If a clinician stores used instruments or a patient retains them for future use, either scenario would be a breach of the Hazardous Waste Regulations 2005. ${ }^{41}$ Sharps have to be stored in clearly labelled boxes and if the dentist is the producer of the hazardous waste it is therefore his/her responsibility to dispose of and not retain this. It is not the patient's responsibility.

\section{Hypochlorite accidents}

Spencer et al. ${ }^{42}$ highlighted the problems of using sodium hypochlorite $(\mathrm{NaOCl})$, the most widely used irrigant in endodontics. It is potentially damaging to clothing, eyes, skin and oral mucosa and should be used with care. Its positive effects at concentrations of $0.5-5 \%$ in endodontics are well documented and it is the only worthwhile irrigant. Endodontics cannot be expected to be successful without its use despite the availability of such products as potassium iodide and chlorhexidine, which are adjunctive to $\mathrm{NaOCl}$. Many practitioners use saline and/or local anaesthetic which in essence achieves nothing other than lubrication. Hydrogen peroxide is a product of the past and its use is never indicated.

However, when $\mathrm{NaOCl}$ is inadvertently extruded through the apical foramen a severe reaction can occur. This problem is possible when the solution is injected into the canal under pressure and with the needle locked into the canal as the solution is placed. Endodontic irrigating syringes are available with luer-lock type attachments and side vent needles to ensure that the irrigant is injected laterally from the needle under minimal pressure rather than forced apically. While the needle should be fine enough to be placed into the apical one third (27-29G), it should always be loose in the canal as the solution is placed. In addition the needle should always be kept on the move while irrigating.

If an accident occurs it can be rapid and very severe, with intense pain despite a local anaesthetic being in place. There will be instant swelling and haemorrhagic exudate may well come into the canal from the apical tissues. The event is more likely to occur with upper central, lateral and canine teeth but there are literature reports of extrusion of the solution with damaging effects into the maxillary sinus and inferior dental (ID) canal. When the problem occurs, reassurance to the patient is needed with advice on what is to be done: increased local anaesthesia for additional pain relief (block anaesthesia if needed), washing of the canal copiously with saline and then drying with paper points and closure of the canal but with no medication.

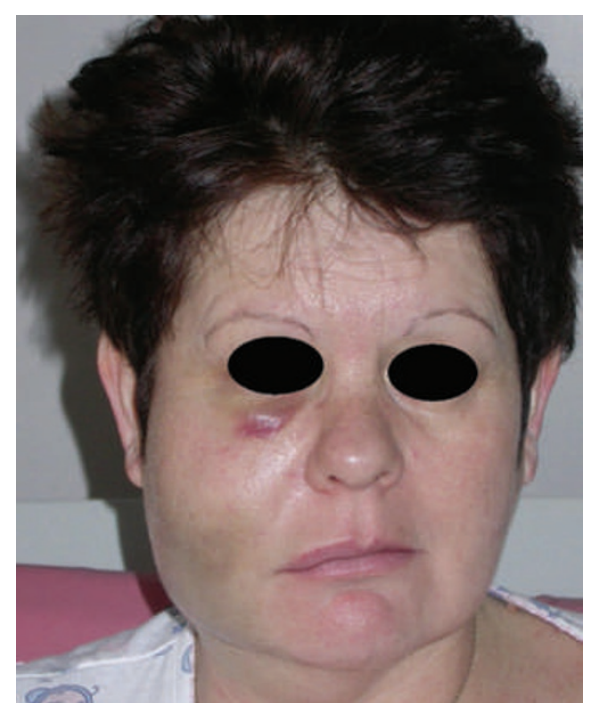

Fig. 11 Severe swelling and bruising as a result of hypochlorite accident (image originally published in Spencer et al. Br Dent J 2007; 202: 555-559) ${ }^{42}$

The patient will possibly have severe swelling and bruising (Fig. 11). Analgesics should be prescribed as well as such drugs as dexamethasone and/or an antihistamine to suppress the inflammatory and allergic aspects. It may be prudent to prescribe antibiotics. Ask the patient to return each day to evaluate signs and symptoms. Telephone regularly to enquire about the patient's welfare. Immediate referral to a hospital casualty department may well be advisable if the reaction is severe and has occurred in proximity to vital structures.

A hypochlorite accident is not intentional but its consequences are severe. Despite best efforts at palliative treatment, a litigious patient may well seek compensation and pursue a claim for negligence. Always contact your defence organisation for advice.

\section{Obturation problems}

Litigious situations under the heading of obturation include overfilling, overextension, underfilling and poorly condensed root filling to name various issues.

The requirements for a good root filling are clearly stated in the ESE guidelines: 'The objectives are: to prevent the passage of microorganisms and fluid along the root canal and to fill the whole canal system, not only to block the apical foramina but also the dentinal tubules and accessory canals. The root filling should be a semisolid material in conjunction with a root canal sealer to fill the voids between the 


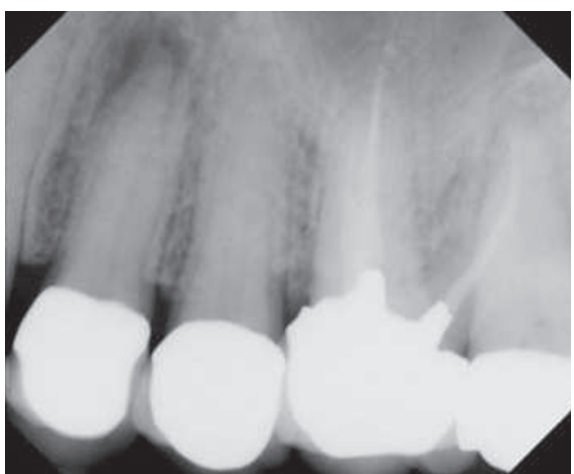

Fig. 12a 24 apical area requires root canal treatment

filling material and the canal wall. The filling should be as close as possible to the apex of the root. Voids should not be seen either within the body of the root filling or at the filling and canal wall junction.

Similarly, pastes are not acceptable to fill root canals, especially those containing aldehydes (N2, Spad, Endomethasone). Due to the flowable nature of some pastes, extrusion is always a possibility and in the lower jaw the inadvertent extrusion of a paste into the ID canal with attendant problems of partial or permanent paraesthesia would be indefensible.

Silver points are no longer acceptable and the American Association of Endodontists has published a position statement on the use of this material. ${ }^{43}$ While accepted as a reasonable root filling material some 30 years ago, it should not be used today as silver points corrode, attract bacteria and perpetuate or cause lesions of endodontic origin. If their use caused a failure of treatment it would be a difficult situation to defend.

Gutta percha is an acceptable material, although were gross extrusion to occur with symptoms and no radiograph had been taken it would be difficult to defend. If good length control has been shown to have taken place - electronic apex locators used and a satisfactory working length radiograph with file and/or GP exposed and extrusion occurs, it would be easier to defend an allegation of negligence.

The fact is that modern techniques of patency and preparation to the apical foramen with filling techniques based on heated gutta percha will result, in some instances, in excess material in the periapical tissues. ${ }^{44}$ While radiographically not very aesthetic, these incidents are not necessarily the cause of failure. Molven et al. ${ }^{45}$ reviewed many

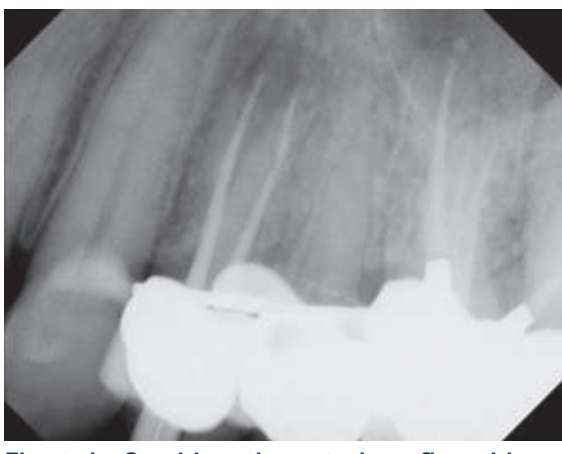

Fig. 12b Good length control confirmed by master cone X-ray. Good tugback ascertained with GP points

root treated cases over a 27 year period and showed many successful outcomes even in the presence of overfilling and excess root filling material (Figs 12a-c). Siqueira has confirmed that bacteria are the cause of endodontic failure, not excess root filling material or a reaction to it, assuming a compatible material such as gutta percha is used. ${ }^{46}$

Root fillings more than $2 \mathrm{~mm}$ short of the radiographic apex are more likely to fail than those at or flush with the radiographic apex. ${ }^{47}$ Despite one's best efforts this scenario could happen. The problem occurs when a restoration is placed on a short root filled tooth. What is the likely response from a patient should swelling and pain ensue after the crown is placed (Figs 13a and b)? The answer to the problem is communication. We are all entitled to have a bad day but the patient must be informed of all issues related to the final outcome. Should you feel the endodontic result does not justify an expensive crown, do not provide one. If you place a crown then you must justify the endodontic outcome to the patient. It is unlikely that a patient will be happy if there is a problem after RCT and a crown. The potential for this problem should be explained in advance.

Remember, an endodontic specialist is always available to advise and if possible treat a case where the clinical result is less than perfect. Of course a patient may refuse a consultation or treatment with a specialist. Record this fact. Communication and record keeping is key in doing one's best within the confines of good practice.

\section{Perforations}

While attempting to find a canal, a perforation is always possible. This can happen

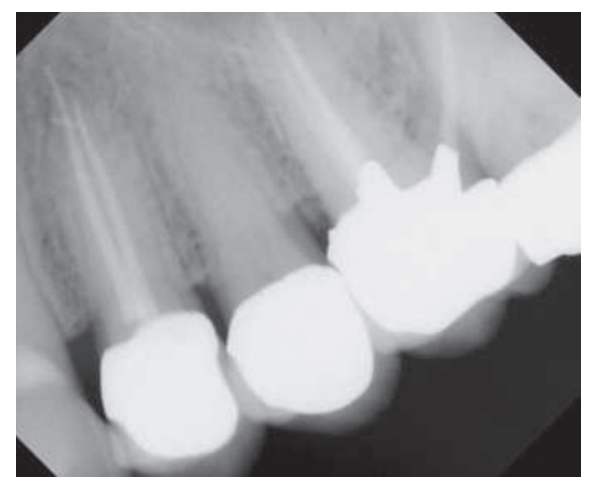

Fig. 12c Despite overfilling of canals 24, healing is seen at one year

on the floor of the pulp chamber or within the confines of the root. The issue here is that if, when starting a root canal, there is the likelihood of a difficulty that could lead to one of the above scenarios, the patient should be informed beforehand. If you cannot locate a sclerosed canal and you perforate attempting to find it but you had advised the patient beforehand that this could happen there is little chance a patient could successfully bring a case

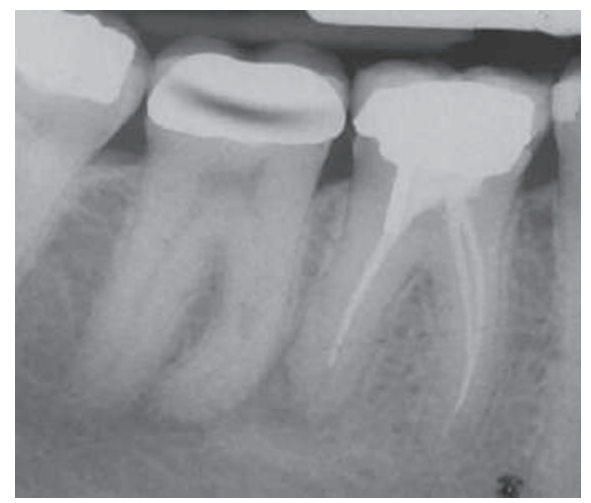

Fig. 13a 46 inadequately root treated.

Minimal radiographic evidence of endodontic disease and the tooth is symptom-free.

An excellent restoration is placed. The option of retreatment was never discussed with the patient

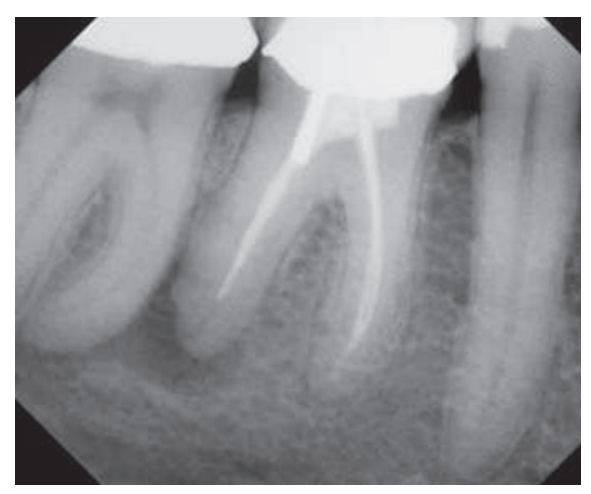

Fig. 13b 46 at six months. Radiographic endodontic disease is now apparent. The patient has pain and swelling and is certainly not happy! 

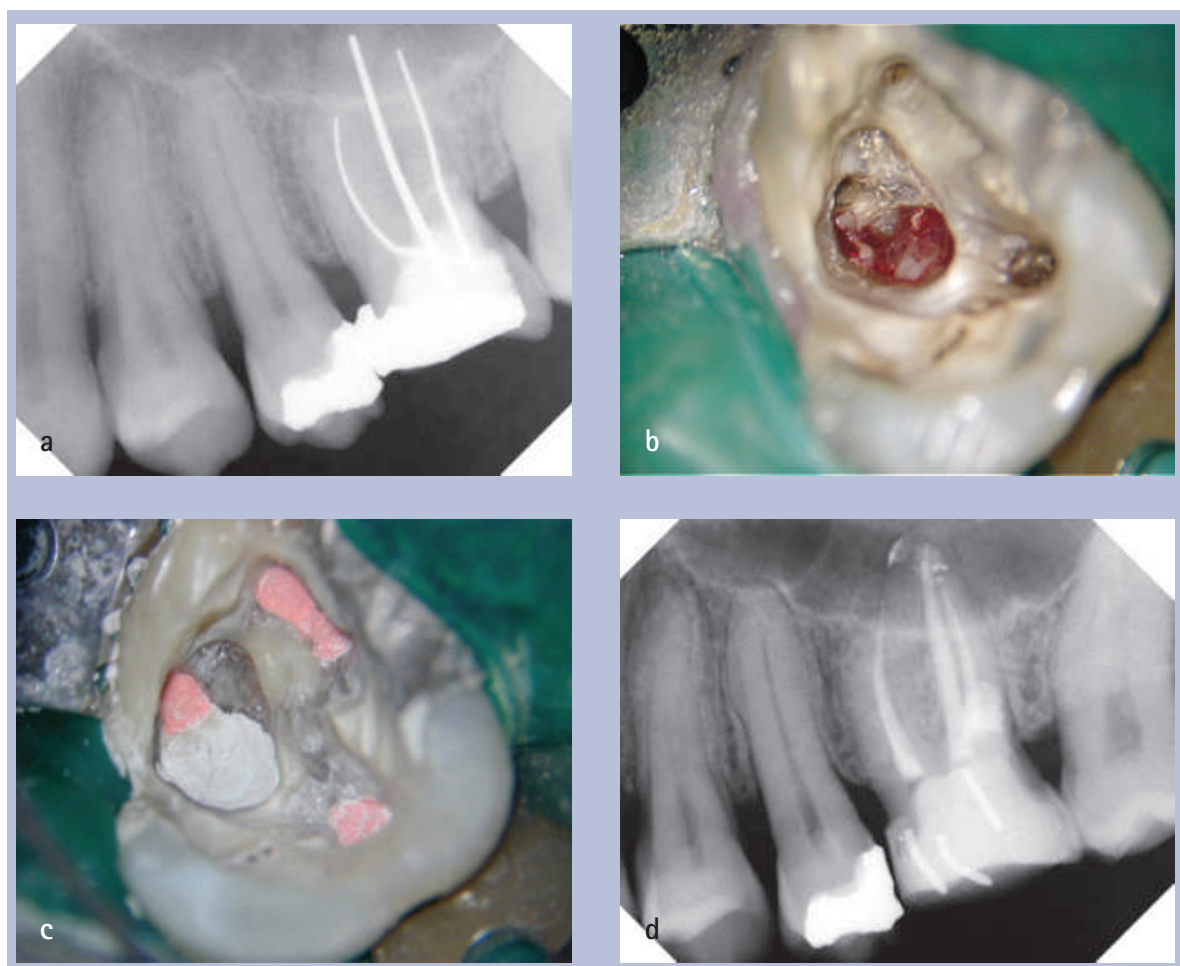

Fig. 14 a) 26 failing silver point case requires root canal retreatment and restoration.

b) Core material and silver points removed to show large perforation of long standing duration on floor of pulp chamber. c) Four canals retreated and perforation sealed with ProRoot MTA (Dentsply Maillefer). d) 26 at one year recall with core build up. Good apical healing and no evidence of pocketing coronally or furcal breakdown related to sealed perforation. The tooth can now be crowned

of negligence. Similarly, if you had recommended a referral which the patient declined but had recorded accurately your conversation with the patient it is unlikely that further action would be successful.

Current wisdom advises that in the case of a perforation, the use of MTA, a product which has been available since 1995, is advisable. ${ }^{48}$ Do you have and do you know what do to do with MTA or should you refer the patient to a specialist? Again, treatment planning involves discussion with the patient and good record keeping in the notes (Figs 14a-d).

\section{CONCLUSIONS}

Endodontic treatment can provide many opportunities for potential litigation by patients, especially where standards of treatment remain poor. Poor quality work with inadequate record keeping is indefensible and failure to communicate outcomes and potential treatment problems lays one open to litigation. Failure to refer, especially if it is felt someone else could obtain a better result, is also indefensible.

The speciality of endodontics is under threat as implants, which can be placed with ease, are seen as an alternative. While the cloud of litigation can affect the decision making process, endodontics can and should be successful. Only by ensuring standards are maintained can we achieve the goal of tooth retention and avoid the unnecessary trauma that accompanies a complaint for negligence from an irate patient.

1. De Cleen M J H, Schuurs A H B, Wesselink PR, Wu $M-K$. Periapical status and prevalence of endodontic treatment in an adult Dutch population. Int Endod J 1993; 26: 112-119

2. Kabak Y, Abbott PV. Prevalence of apical periodontitis and the quality of endodontic treatment in an adult Belarussian population. Int Endod J 2005; 38: 238-245.

3. Dugas N N, Lawrence H P, Teplitsky P E, Pharoah $M$ J, Friedman S. Periapical health and treatment quality assessment of root filled teeth in two Canadian populations. Int Endod J 2003; 36: 181-192.

4. Loftus J J, Keating A P, McCartan B E. Periapical status and quality of endodontic treatment in an adult Irish population. Int Endod J 2005; 38: 81-86.

5. Lupi-Perquirier L, Bertrand M F, Muller-Bolla M, Rocca J P, Bolla M. Periapical status and quality of endodontic treatment in an adult French population. Int Endod J 2002; 35: 690-697.

6. Jimenez-Pinzon A, Segura-Egea J J, Poyato-Ferrera $M$, Velasco-Ortega E, Rios Santo J V. Prevalence of apical periodontitis and frequency of root filled teeth in an adult Spanish population. Int Endod J 2004; 37: 167-173.

7. Kirkevang L L, Horstad-Bindslev P, Orstavik D, Wenzel A P. Prevalence of apical periodontitis and frequency of root filled teeth in an urban Danish population. Int Endod J 2001; 34: 198-205.
8. European Society of Endodontology. Consensus report of the European Society on quality quidelines for endodontic treatment. Int Endod J 1994, 27: 115-124.

9. European Society of Endodontology. Consensus report of the European Society on quality quidelines for endodontic treatment. Int Endod J 2006; 39: 921-930.

10. Dummer PM H. The quality of root canal treatment provided by general dental practitioners working within the general dental services of England and Wales. Part 1. Dental Profile (J Dent Prac Board Eng Wales) 1997: 17: 5-6.

11. Dummer PM H. The quality of root canal treatment provided by general dental practitioners working within the general dental services of England and Wales. Part 2. Dental Profile (J Dent Prac Board Eng Wales) 1998; 19: 8-10.

12. McColl E, Smith M, Whitworth J, Seccombe G, Steele J. Barriers to improving endodontic care: the views of NHS practitioners. Br Dent J 1999; 186: $564-568$.

13. Jenkins S M, Hayes S J, Dummer P M. A study of endodontic treatment carried out in dental practice within the UK. Int Endod J 2001; 34: 16-22.

14. General Dental Council. Standards for dental professionals. London: GDC, 2005. www.gdc-uk.org.

15. General Dental Council. Principles of patient consent. London: GDC, 2005. www.gdc-uk.org.

16. Field J W, Guttman J L, Solomon E S, Rakusin H. A clinical radiographic retrospective assessment of the success rate of single visit root canal treatment. J Endod 2006; 32: 822-827.

17. Lazarski M P, Walker W A 3rd, Flores C M, Schindler W G, Hargreaves K M. Epidemiological evaluation of the outcomes of non surgical root canal treatment in a large cohort of insured dental patients. J Endod 2001; 27: 791-796.

18. American Association of Endodontists. Endodontic case difficulty assessment form. Chicago: AAE 2005. http://www.aae.org/rootcanalspecialists/dentalprofessionalsandstudents/casedifficulty.htm.

19. Iqbal M K, Kim S. For teeth requiring endodontic treatment, what are the differences in outcomes of restored endodontically treated teeth compared to implant-supported restorations? Int J Oral Maxillofac Implants 2007: 22(Suppl): 96-116.

20. Friedman S, Mor C. The success of endodontic therapy - healing and functionality. J Calif Dent Assoc 2004; 32: 493-503.

21. Abou-Rass M. The stressed pulp condition: an endodontic-restorative diagnostic concept. J Prosthet Dent 1982; 48: 264-267.

22. Cheung G S, Lai S C, Ng R P. Fate of vital pulp beneath a metal-ceramic crown or a bridge retainer. Int Endod J 2005; 38: 521-530.

23. Shabahang $\mathrm{S}$, Goon N W, Gluskin A H. An in vivo evaluation of Root ZX electronic apex locator. J Endod 1996; 22: 616-618.

24. Whitworth J M, Seccombe G V, Shoker K, Steele J G. Use of rubber dam and irrigant selection in UK general dental practice. Int Endod J 2000; 33: 435-441.

25. Susini G, Pommel L, Camps J. Accidental ingestion and aspiration of root canal instruments and other dental foreign bodies in a French population. Int Endod J 2007; 40: 585-589.

26. Ng C C, Dumbrique H B, Al-Bayat M I, Griggs J A Wakefield $C$ W. Influence of remaining coronal tooth structure location on the fracture resistance of restored endodontically treated teeth. J Prosthet Dent 2006; 95: 290-296.

27. Seow L L, Toh C G, Wilson N H. Remaining tooth structure associated with various preparation designs for the endodontically treated maxillary second premolar. Eur J Prosthodont Restor Dent 2005; 13: 57-64.

28. Trope M, Tronstad L. Resistance to fracture of endodontically treated premolars restored with glass ionomer cement or acid etch composite resin. J Endod 1991; 17: 257-259.

29. Chailertvanitkul P, Saunders W P, Saunders E, Mackenzie D. An evaluation of microbial coronal leakage in the restored pulp chamber of root canal treated multirooted teeth. Int Endod J 1997; 30: 318-322. 
30. Nagasiri R, Chitmongkolsuk S. Long-term survival of endodontically treated molars without crown coverage: a retrospective cohort study. J Prosthet Dent 2005; 93: 164-170.

31. Bahcall J K, Carp S, Miner M, Skidmore L. The causes, prevention, and clinical management of broken endodontic rotary files. Dent Today 2005; 24(11): 74, 76, 78-80.

32. Sattapan B, Palamara J E, Messer H H. Torque during canal instrumentation using rotary nickeltitanium files. J Endod 2000; 26: 156-160.

33. Sattapan B, Nervo G J, Palama J E, Messer H H. Defects in rotary nickel-titanium files after clinical use. J Endod 2000; 26: 161-165

34. Pruett J P, Clement D J, Carnes D L Jr. Cyclic fatigue testing of nickel-titanium endodontic instruments. J Endod 1997; 23: 77-85.

35. Yared G M, Dagher F E, Machtou P, Kulkarni G K. Influence of rotational speed, torque and operator proficiency on failure of greater taper files. Int Endod J 2002; 35: 7-12.

36. Gambarini G. Rationale for the use of low-torque endodontic motors in root canal instrumentation.
Endod Dent Traumato/ 2000; 16: 95-100.

37. Saunders J L, Eleazar P D, Zhang P, Michalek S. Effect of separated instrument on bacterial penetration of obturated root canals. J Endod 2004; 30: 177-179.

38. Fors $\mathrm{U} \mathrm{G} \mathrm{H}$, Berg J O. Endodontic treatment of root canals obstructed by foreign objects. Int Endod $J$ 1986; 19: 2-10.

39. Department of Health. Advice for dentists on re-use of endodontic instruments and variant CreutzfeldtJakob disease (VCJD). London: Department of Health, 2007. Gateway Reference Number 8100.

40. Head M W, Ritchie D, McLoughlin V, Ironside J W. Investigation of PrPres in dental tissues in variant CJD. Br Dent J 2003; 195: 339-343.

41. Hazardous Waste (England and Wales) Regulations 2005. London: The Stationery Office, 2005.

42. Spencer H R, Ike V, Brennan P A. Review: the use of sodium hypochlorite in endodontics - potential complications and their management. Br Dent J 2007; 202: 555-559.

43. American Association of Endodontists Clinical Practice Committee. AAE position statement. Use of silver points. Chicago: AAE, 2007. http://www.aae. org/dentalpro/guidelines.htm.

44. Da Silva D, Endal U, Reynaud A, Portenier I, Orstavik D, Haapasalo M. A comparative study of lateral condensation, heat-softened gutta-percha and a modified master cone heatsoftened backfilling technique. Int Endod J 2002 35: 1005-1011.

45. Molven O, Halse E, Fristad I. Periapical changes following root canal treatment observed 20-27 years postoperatively. Int Endod J 2004; 35: 784-788.

46. Siqueira J F Jr. Aetiology of root canal treatment failure: why well root treated teeth fail. Int Endod J 2001; 34: 1-10.

47. Chugal N M, Clive J M, Spangberg L S. Endodontic infection: some biological treatment factors associated with outcome. Oral Surg Oral Med Oral Pathol Oral Radiol Endod 2003; 96: 81-90

48. Pitt Ford T R, Torabinejad M, McKendry D J, Hong C U, Kariyawasam S P. Use of mineral trioxide aggregate for repair of furcal perforations. Oral Surg Oral Med Oral Pathol Oral Radiol Endod 1995; 79: 756-763. 